EESTI NSV TEADUSTE AKADEEMIA TOIMETISED. XV KÖIDE

FUUSIKA-MATEMAATIKA- JA TEHNIKATEADUSTE SEERIA. 1966, NR. 3

ИЗВЕСТИЯ АКАДЕМИИ НАУК ЭСТОНСКОН ССР. ТОМ ХV

СЕРИЯ ФИЗИКО-МАТЕМАТИЧЕСКИХ И ТЕХНИЧЕСКИХ НАУК. 1966, № 3

А. ААРНА, Л. МЭЛДЕР, Э. СИИМЕР

\title{
НЕКОТОРЫЕ НОВЫЕ ПРЕДСТАВЛЕНИЯ О СВОЙСТВАХ СЛАНЦЕВОЙ СМОЛЫ
}

Сланцевая смола в последние годы приобретает все большее значение как сырье для получения химических продуктов. В связи с этим возникает необходимость ее разделения на групповые компоненты и в дальнейшем, по возможности, на индивидуальные соединения. На современном этапе развития химической промышленности понятно, что получение различных химических веществ возможно только из сырья с определенными химическими свойствами. Использование смесей соединений для химического синтеза не может дать качественных конечных продуктов, так как управление химимескими реакциями не представляется возможным.

Научно-исследовательские работы, проведенные за последние десять лет, дали достаточно хорошее представление о химическом групповом составе сланцевой смолы. $\mathrm{B}$ результате исследований Института химии АН ЭССР за последние годы получены подробные данные об индивидуальном составе низкокипящих фракций смолы. На основании проделанных работ можно заключить, что в состав смолы полукоксования прибалтийских горючих сланцев входят следующие основные группы соединений:

1) парафиновые углеводороды нормального и изо-строения;

2) непредельные углеводороды - алифатические и циклические олефины и диолефины;

3) ароматические углеводороды бензольного ряда и с конденсированными циклами;

4) нафтеновые углеводороды;

5) фенолы - одно- и двухатомные, с конденсированными ароматическими ядрами, гетероциклические;

6) карбоновые кислоты нормального строения;

7) кетоны - алифатические, циклические и ароматические;

8) хиноны -9 , 10-антрахинон;

9) простые эфиры;

10) сернистые соединения - производные тиофена и тионафтена, сульфиды, дисульфиды, меркаптаны;

11) азотистые соединения - пиридиновые основания.

Понятно, что в столь сложной смеси каждая группа соединений не сохраняет все свои специфические свойства. Более вероятно, что в сланцевой смоле происходит физико-химическое взаимодействие между отдельными ее составляющими, в результате чего химические и физические свойства отдельных групповых компонентов частично теряют свою специфику, а смесь приобретает совершенно новые свойства. Авторы на- 
стоящей статьи проводили в последние годы систематическое исследование межмолекулярных явлений с целью установления принципиальных возможностей разделения сланцевой смолы $[1-4]$.

На первом этапе наших исследований особое внимание уделялось образованию водородной связи, как явлению, происходящему между составляющими смолы. Известно, что кислородные и азотистые соединения легко образуют внутри- и межмолекулярные водородные связи:

И. Т. Д

$$
\begin{aligned}
& \mathrm{R}-\mathrm{OH} \ldots \mathrm{O}= \\
& \mathrm{R}-\mathrm{OH} \ldots \mathrm{N} \equiv
\end{aligned}
$$

Спектроскопическими и калориметрическими методами определена энергия водородной связи между компонентами в бинарных системах, а также между некоторыми составляющими сланцевой смолы. В табл. 1 приводятся характерные результаты этих исследований.

Таблица ।

\begin{tabular}{|c|c|c|}
\hline Қомпонент $A$ & Компонент $B$ & $\begin{array}{c}\text { Энергия водородной } \\
\text { связи, ккал/моль }\end{array}$ \\
\hline $\begin{array}{l}\text { Одноатомный фенол (произ- } \\
\text { водный фенола или наф- } \\
\text { тола) }\end{array}$ & $\begin{array}{l}\text { Простой эфир } \\
\text { Сложный эфир } \\
\text { Кетон } \\
\text { Амин }\end{array}$ & $\begin{array}{l}2,4-6,9 \\
2,7-7,3 \\
3,9-7,2 \\
5,6-10,3\end{array}$ \\
\hline $\begin{array}{l}\text { Двухатомный фенол (произ- } \\
\text { водный пирокатехина п.ли } \\
\text { резорцина) }\end{array}$ & $\begin{array}{l}\text { Простой эфир } \\
\text { Сложный эфир } \\
\text { Кетон } \\
\text { Амин }\end{array}$ & $\begin{array}{l}2,0-4,9 \\
3,3-7,4 \\
5,5-6,2 \\
5,6-8,3\end{array}$ \\
\hline $\begin{array}{l}\text { Одноатомный фенол (пронз- } \\
\text { водный фенола) }\end{array}$ & $\begin{array}{l}\text { Кетоны средних фракций } \\
\text { сланцевой смолы }\end{array}$ & $5-7$ \\
\hline $\begin{array}{l}\text { Фенолы сланцевой под- } \\
\text { смольной воды }\end{array}$ & $\mathrm{Ke} \mathrm{T} \mathrm{O} \mathrm{H}$ & $5-7$ \\
\hline
\end{tabular}

Энергия связи некоторых молекулярных комплексов

Проведенные исследования показывают, что энергия водородной связи значительно превышает энергию обычных ван-дер-ваальсовых сил и тем самым должна оказать существенное влияние на процесс разделения сланцевой смолы. Образование водородной связи должно сказываться, в первую очередь, при дистилляции сланцевой смолы. Р. Эвель, Ч. Харрисон и Л. Берг [5] считают, что образование водородной связи является главной причиной появления азеотропных систем. Другие формы межмолекулярных сил, как дипольные и индукционные силы, играют подчиненную роль. Если смесь состоит из компонентов $A$ и $B$, то в зависимости от энергии ассоциации между одинаковыми и различными молекулами можно представить следующие три возможности:

$$
E_{A-A}=E_{B-B}=E_{A-B}
$$

т. е. межмолекулярные силы между всеми молекулами примерно одинаковы. В таком случае не наблюдается существенных отклонений от закона Рауля, и дистилляция протекает нормально. 


$$
E_{A-A}=E_{B-B}>E_{A-B}
$$

Здесь имеет место положительное отклонение от закона Рауля, вследствие чего возможно образование положительного азеотрона. Упругость паров смеси компонентов $A$ и $B$ выше, чем у индивидуальных компонентов в отдельности и, следовательно, температура кипения смеси ниже температуры кипения компонентов.

3.

$$
E_{A-A}=E_{B-B}<E_{A-B}
$$

В этом случае имеет место отрицательное отклонение от закона Рауля, и температура кипения смеси выше температуры кипения чистых компонентов.

В. Свентославский [6] развивал теорию азеотропных систем, в частности, применительно к каменноугольной смоле. Он же ввел понятие полиазеотропных смесей, подразумевая под этим термином сложные системы, которые содержат две или более серии соединений, образующих азеотропы с другими сериями.

Наличие в сланцевой смоле водородных связей заставляет рассматривать ее как сложную полиазеотропную смесь. Можно полагать, что дистилляция сланцевой смолы как полиазеотропной системы проходит в два этапа:

1) дистилляция кипящих до $150^{\circ} \mathrm{C}$ фракций, в которых содержание кислородных соединений ничтожно, и

2) дистилляция средних фракций, в состав которых входят углеводороды, фенолы, карбоновые кислоты и нейтральные кислородные соединения.

Во фракции до $150^{\circ}$ возможно образование двух- и трехкомпонентных азеотропных систем из ароматических, предельных и непредельных углеводородов. По данным О. Эйзена и С. Ранг $\left[{ }^{7}, 8\right], 7$ предельных и 17 непредельных углеводородов составляют $55,3 \%$ от общего количества фракции легкого бензина $\left(60-150^{\circ}\right)$, но удельный вес ни одного из них не превышает $7 \%$. Содержание ароматических и сернистых соединений равно примерно 6\%. Следовательно, в сланцевом бензине отсутствует главный компонент дистилляции.

Непредельные углеводороды, общее содержание которых в бензине достигает $60 \%$, образуют при дистилляции двухкомпонентные положительные азеотропные системы с ароматическими углеводородами (и сернистыми соединениями типа тиофена), а также трехкомпонентные системы с предельными и ароматическими (в том числе тиофеновыми) соединениями до тех пор, пока из смеси не перегоняются ароматические углеводороды с соответствующим азеотропным пределом. Поэтому надо полагать, что ароматические углеводороды появляются в дистилляте значительно ниже (примерно на $20^{\circ}$ ) их истинных температур кипения и перегоняются полностью в интервале нескольких градусов аналогично дистилляции нефти. Парафиновые и нафтеновые углеводороды, образующие с олефинами двухкомпонентные положительные азеотропы, температура кипения которых незначительно отличается от температур кипения компонентов (узкий азеотропный предел), перегоняются также несколько ниже их истинных температур кипения. Непредельные углеводороды появляются в дистилляте ниже своих температур кипения, однако значительное количество из них выкипает (после образования 
соответствующих азеотропов с предельными и ароматическими соединениями) раздельно при своей истинной температуре кипения.

Более сложная картина наблюдается при дистилляции в присутствии кетонов. Известно, что кетоны образуют положительные азеотропные смеси с углеводородами. В табл. 2 приводятся для примера некоторые данные для ацетона и метилэтилкетона [9].

Таблица 2

Азеотропные смеси ацетона и метилэтилкетона с углеводородами [9]

\begin{tabular}{|c|c|c|c|}
\hline \multirow[b]{2}{*}{ Компонент $B$} & \multirow[b]{2}{*}{$\begin{array}{l}\text { Температура } \\
\text { кипения, }{ }^{\circ} \mathrm{C}\end{array}$} & \multicolumn{2}{|c|}{ Азеотропная смесь } \\
\hline & & $\begin{array}{l}\text { Температура } \\
\text { кипения, }{ }^{\circ} \mathrm{C}\end{array}$ & $\begin{array}{c}\% \\
\text { кетона }\end{array}$ \\
\hline $\mathrm{A}=$ а цетон & 56,35 & & \\
\hline 2-Метилбутан & 27,95 & 26 & 20 \\
\hline H-Пентан & 36,2 & 32 & 20 \\
\hline Бензол & 80,2 & $\overline{561}$ & - \\
\hline $\begin{array}{l}\text { 1,3-Циклогексадиен } \\
\text { Циклогексан }\end{array}$ & $\begin{array}{l}80,8 \\
80,75\end{array}$ & $\begin{array}{l}56,1 \\
54,0\end{array}$ & $\overline{85}$ \\
\hline 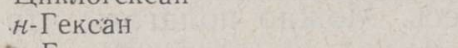 & 68,95 & 49,8 & 59 \\
\hline н-Гептан & 98,45 & - & - \\
\hline $\mathrm{A}=\mathrm{м} \mathrm{етилэтилкет} \mathrm{О} \mathrm{п}$ & 79,6 & & \\
\hline Бензол & 80,2 & 78,4 & 62,5 \\
\hline Циклогексан & 80,75 & 72 & 40 \\
\hline н-Гексан & 68,95 & 64.2 & 37 \\
\hline 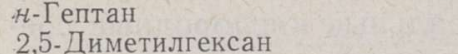 & $\begin{array}{r}98,5 \\
109,3\end{array}$ & $\underline{77,0}$ & $\underline{70}$ \\
\hline & & & \\
\hline
\end{tabular}

Как видно из данных табл. 2, кетоны способны образовывать азеотропы с углеводородами, температура кипения которых отличается от температуры кипения кетона примерно на $30^{\circ}$. Поэтому при дистилляции сланцевого бензина следы ацетона должны появляться в дистилляте уже при температуре примерно $26^{\circ}$.

Средние фракции смолы содержат значительное количество кетонов. Можно полагать, что высшие кетоны при дистилляции подчиняются таким же закономерностям. Исходя из этого, при дистилляции обесфеноленной смолы кетоны должны появляться в дистилляте ниже своих истинных температур кипения.

Ход дистилляции, однако, должен существенно измениться при дистилляции средних фракций необесфеноленной смолы. В табл. 3 приводятся некоторые данные для азеотропных смесей фенолов.

Из приведенных в табл. 3 данных видно, что фенолы образуют с кетонами отрицательные азеотропы, температура кипения которых выше температур кипения исходных компонентов. С углеводородами фенолы, как и кетоны, образуют положительные азеотропные смеси, в результате чего при дистилляции средних фракций сланцевой смолы наблюдается образование сложных положительно-отрицательных азеотропных систем, а каждый компонент распределяется в широком интервале температур. Учитывая высокое содержание фенолов и кетонов в необесфеноленных средних фракциях, можно полагать, что основная масса их перегоняется выше своих истинных температур кипения.

Такой вывод хорошо совпадает с практическими результатами, полученными при исследовании кетонов сланцевой смолы. Так, например, были найдены: 
предель кипения исходной фракциии

до $200^{\circ}$ перегоняется $41 \%$ до $250^{\circ}$ перегоняется $69 \%$ конец кипения $291^{\circ}$ предель кипения выделеніых КетОнов

до $200^{\circ}$ перегоняется $73 \%$

до $225^{\circ}$ перегоняется $92 \%$

По-видимому, этим же объясняется высокое содержание низкокипящих фенолов в остатке и незначительное содержание фенолов в дизельной фракции, получаемой на установке дистилляции смолы СПК им. В. И. Ленина.

таблица 3

\section{Азеотропные смеси фенолов [9]}

\begin{tabular}{|c|c|c|c|}
\hline \multirow[b]{2}{*}{ Компонент $B$} & \multirow[b]{2}{*}{$\begin{array}{l}\text { Температура } \\
\text { кипения, }{ }^{\circ} \mathrm{C}\end{array}$} & \multicolumn{2}{|c|}{ A зеотро о } \\
\hline & & $\begin{array}{l}\text { Температура } \\
\text { кипения. }{ }^{\circ} \mathrm{C}\end{array}$ & $\begin{array}{c}\% \\
\text { фенола }\end{array}$ \\
\hline 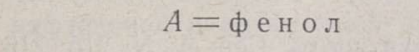 & 182,2 & & \\
\hline $\begin{array}{l}\text { В-Пиколин } \\
\text { Циклогексанон } \\
\text { Анизол } \\
\text { Ацетофенон } \\
\text { Пропилбензон } \\
\text { Нафталин }\end{array}$ & $\begin{array}{l}143,5 \\
155 \\
153,85 \\
202,05 \\
158,9 \\
218,05\end{array}$ & $\begin{array}{l}186,2 \\
184,5 \\
- \\
202,25 \\
158,0 \\
-\end{array}$ & $\begin{array}{l}42 \\
72 \\
-7,8 \\
4 \\
-\end{array}$ \\
\hline$A=м-$ крезол & 202,2 & & \\
\hline $\begin{array}{l}\text { Ацетофенон } \\
\text { Нафталин }\end{array}$ & $\begin{array}{l}202,05 \\
218,05\end{array}$ & $\begin{array}{l}208,45 \\
202,08\end{array}$ & $\begin{array}{l}47,2 \\
97,2\end{array}$ \\
\hline $\mathrm{A}=$ пирокатехин & 245,2 & & \\
\hline $\begin{array}{l}\text { Метил-н-толилкетон } \\
\text { Нафталин } \\
\text { Дифенилоксид }\end{array}$ & $\begin{array}{l}226,35 \\
218,05 \\
259,3\end{array}$ & $\begin{array}{l}246,3 \\
217,45 \\
242,0\end{array}$ & $\begin{array}{l}87,5 \\
11,5 \\
59,3\end{array}$ \\
\hline
\end{tabular}

Таким образом, сланцевая смола с точки зрения ее разделения представляет собой очень сложную смесь, в которой возможно образование положительных, отрицательных и положительно-отрицательных азеотропных смесей. Исходя из этого, дистилляция сланцевой смолы на фракции с определенными свойствами по аналогии с каменноугольной смолой или нефтью невозможна.

Если ставить задачу разделить сланцевую смолу на определенные фракции для выделения, например, фенолов, то применение высокоэффективной ректификационной колонны не имеет никакого практического значения, так как пределы кипения выделенных фенолов не совпадают с пределами кипения исходной фракции. Поэтому для первичной разгонки сланцевой смолы можно ограничиваться простой дистилляцией

Для увеличения выхода фенолов, в том числе более низкокипящих, необходимо подвергать обесфеноливанию более широкую фракцию. Понятно, что с обесфеноливанием широкой фракции смолы возрастает и расход щелочи или любого другого реагента для обесфеноливания. Поэтому точное установление предела кипения широкой фракции является предметом более подробного экономического и технического исследования. 


\section{Выводы}

1. В результате сушествования в сланцевой смоле водородных связей в ней происходит образование азеотропных систем.

2. Вследствие образования положительных, отрицательных и положительно-отрицательных полиазеотропных систем имеет место значительное искажение истинных температур кипения отдельных групповых компонентов сланцевой смолы.

3. Для первичной разгонки сланцевой смолы нет необходимости использовать сложные ректификационные аппараты. Для увеличения выхода фенолов целесообразно подвергать обесфеноливанию более широкую фракцию сланцевой смолы.

\section{ЛИ Т Е РА Т У Р А}

1. А а рн а А. Я., Мэлде р Л. И., Тр. Таллинск. политехн. ин-та. Сер. А, № 185 , 304 (1960); № 185, 317 (1960); № 195, 15 (1962); № 195, 21 (1962).

2. А а р н а А., Мэлде р Л., Изв. АН ЭССР. Сер. физ.-матем. и техн. наук, 13 , № 1 , 10 (1964).

3. М элд е р Л. И., А лев М. О., Тр. Таллинск. политехн. ин-та. Сер. А, № 210, 75 (1964).

4. А а р н а А. Я., Си й м е р Э. Х., Тр. Таллинск. политехн. ин-та. Сер. А, № 215,213 (1964); № 215, 217 (1964); № 215, 229 (1964).

5. E w ell R. H., Harriss o n J. M., B e r g L., Ind. Eng. Chem., 36, 871 (1944).

6. С в ен то сл а в ски й В. В., Физическая химия каменноугольной смолы, М., 1958.

7. Эйз ен О. Г., Р ан г С. А., Сб. Горючие сланцы, вып. 4, 171 и 200 (1961).

8. Р а н г С. А., Сб. Горючие сланцы, вып. 4, 182 (1961).

9. Хорсли Л., Таблицы азеотропных смесей, М., 1951.

Таллинский политехнический институт

Поступила в редакцию $31 / \mathrm{V} 1965$

\section{A. AARNA, L. MOLDER, E. SIIMER}

\section{UUSI VAATEID PÓLEVKIVIÓLI OMADUSTELE}

Uurimistöödega selgitati, et põlevkiviōlis esinevad suures ulatuses molekulidevahelised vesiniksidemed, mis pōhjustavad aseotroopsete segude tekkimist õli destillatsioonil. Polüaseotroopsed süsteemid tekivad süsivesinike ja hapnikuühendite puhul. Tingituna aseotroopsete süsteemide esinemisest ei anna põlevkiviõli destillatsioon fraktsioone soovitud komponentide sisaldusega, vaid üksikute ühendirühmade keemistemperatuurid on tugevasti moonutatud. Seetōttu pole otstarbekohane põlevkiviõli primaarsel destillatsioonil rakendada körge efektiivsusega rektifikatsiooniseadmeid, vaid esimeses astmes tuleb taotleda maksimaalset õli lahutamist keemiliste omaduste järgi.

\section{A. AARNA, L. MÖLDER, E. SIIMER}

\section{NEUE ERKENNTNISSE UBER DIE CHEMISCHEN EIGENSCHAFTEN DES BRENNSCHIEFERÖLS}

Durch systematische Untersuchungen wurde erwiesen, dass zwischenmolekulare Wasserstoffbrücken im Brennschieferöl in grossem Umfang vorhanden sind. Die Wasserstoffbrücken beeinflussen die Bildung azeotroper Gemische, besonders bei sauerstoffhaltigen Verbindungen (Phenole, Ketone, Äther). Unter Bezugnahme der Azeotropenbildung kann eine Primärdestillation des Brennschieferöls unter Verwendung einer effektiven Rektifikationskolonne keine befriedigende Trennung des Brennschieferöls sichern, soweit einzelne Gruppenbestandteile des Öls zwischen den Fraktionen verteilt sind. Im Interesse der Trennung der chemischen Bestandteile des Brennschieferöls wird es zweckmässig sein, seine primäre Trennung nach den chemischen Eigenschaften durchzuführen. 